\title{
Statin use and risk of recurrent venous thrombosis: results from the MEGA follow-up study
}

\author{
Sigrid K. Brækkan PhD ${ }^{1,2}$ | Camila Caram-Deelder MSc ${ }^{1,3}$ | Bob Siegerink PhD ${ }^{1,4,5}$ \\ Astrid van Hylckama Vlieg PhD ${ }^{1}$ | Saskia le Cessie PhD, Professor ${ }^{1,6}$ | \\ Frits R. Rosendaal PhD, Professor ${ }^{1,3}$ | Suzanne C. Cannegieter PhD, Professor ${ }^{1,3}$ | \\ Willem M. Lijfering $\mathrm{PhD}^{1,3}$
}

${ }^{1}$ Department of Clinical Epidemiology, Leiden University Medical Center, Leiden, the Netherlands

${ }^{2}$ K.G Jebsen Thrombosis Research and Expertise Center (TREC), University of Tromsø, Tromsø, Norway

${ }^{3}$ Center for Clinical Transfusion Research, Sanquin Research, Leiden, the Netherlands

${ }^{4}$ Einthoven Laboratory of Experimental Vascular Medicine, Leiden University Medical Center, Leiden, the Netherlands

${ }^{5}$ Center for Stroke Research Berlin, Charité Universitätsmedizin Berlin, Berlin, Germany

${ }^{6}$ Department of Medical Statistics and Bioinformatics, Leiden University Medical Center, Leiden, the Netherlands

\section{Correspondence}

Sigrid K. Brækkan, K.G. Jebsen TREC, Department of Clinical Medicine, Fakulty of Health Sciences, University of Troms $\varnothing$, Tromsø, Norway.

Email: Sigrid.brakkan@uit.no

Funding information the Netherlands Heart Foundation, Grant/ Award Number: NHS98.113, NHS2010B167, NHS208B086 and NHS2011T012; Dutch Cancer Foundation, Grant/Award Number: RUL 99/1992; the Netherlands Organization for Scientific Research, Grant/Award Number: 912-03-033|2003

\begin{abstract}
Introduction: Whether statin use after first venous thrombosis reduces the risk of recurrence is uncertain. Therefore, we aimed to examine the risk of recurrent venous thrombosis in statin users vs non-users.

Methods: Patients with a first venous thrombosis were recruited from the MEGA followup study. Information on statin use was obtained by linkage to the Dutch Foundation for Pharmaceutical Statistics register. Linkage was successful in $54 \%$ of all patients $(n=2,547)$. Cox-regression models with statin-exposure as a time-dependent co-variate were used to estimate hazard ratios (HR) with 95\% confidence intervals (Cl 95) for recurrence.

Results: Statin therapy was continued in 153 (6.0\%) patients and initiated in 233 (9.1\%) patients during a median follow-up of 5.7 years. There were 367 recurrent venous thrombotic events, of which 32 occurred among statin users. Incident statin use was associated with $22 \%$ reduced risk of recurrence after multivariable adjustments ( $\mathrm{HR} 0.78, \mathrm{Cl} 95$ : $0.46-1.31$ ), and $13 \%$ reduced risk after propensity score adjustment ( $\mathrm{HR} 0.87, \mathrm{Cl} 95$ : 0.521.47). Statin use seemed not to have an effect on recurrence in patients with an unprovoked first event (multivariable HR 1.03, Cl 95: 0.54-1.98), but the statistical power was low due to few events and the results must be interpreted with caution. In general, the risk estimates were slightly attenuated when prevalent users were included in the analyses. Conclusion: Our findings suggest that statins may have a modest decreasing effect on the risk of recurrent venous thrombosis. While we took care to minimize bias and confounding, the causality of the association is still unsettled.
\end{abstract}

\section{KEYWORDS}

deep vein thrombosis, pulmonary embolism, recurrence, statins, venous thrombosis

\section{Essentials}

- Whether statin use after first venous thrombosis reduces the risk of recurrence is uncertain.

- We examined the risk of recurrent venous thrombosis in statin users versus non-users.

- Incident statin use was associated with a $22 \%$ reduced risk of recurrence.

- Statins may have a modest decreasing effect on the risk of recurrent venous thrombosis.

This is an open access article under the terms of the Creative Commons Attribution-NonCommercial-NoDerivs License, which permits use and distribution in any medium, provided the original work is properly cited, the use is non-commercial and no modifications or adaptations are made.

(c) 2017 The Authors. Research and Practice in Thrombosis and Haemostasis published by Wiley Periodicals, Inc on behalf of International Society on Thrombosis and Haemostasis. 


\section{INTRODUCTION}

Venous thrombosis (ie, deep vein thrombosis (DVT) and pulmonary embolism) is a common, serious disorder with potentially fatal outcome. The rate of recurrence in patients with a first venous thrombosis is approximately $3-5 \%$ per year, and the 30 -day mortality rate is around $6 \%{ }^{1,2}$ Currently, the only effective strategy to prevent recurrent venous thrombosis is to continue anticoagulation indefinitely. However, treatment with anticoagulants carries a risk of major bleeding complications, and new treatment modalities with a better benefit-harm relationship are needed for long-term secondary prevention of recurrent venous thrombosis.

The observed association between venous and arterial thrombosis led to the hypothesis that pharmacological interventions that decrease the risk of arterial thrombosis would also decrease the risk of venous thrombosis. ${ }^{3,4}$ Statins are efficient drugs used in primary and secondary prevention of arterial thrombosis. ${ }^{5,6}$ Recent studies, including randomized trials, have reported that statin use may be associated with up to $40 \%$ reduced risk of first venous thrombosis, ${ }^{7}$ which association seemed dependent on the type of statin and the clinical features of the population studied. ${ }^{8,9}$ The clinical utility of statins in primary prevention of venous thrombosis will be low, since the small absolute benefit of statin treatment is likely to be counteracted by similar or even more harmful side-effects, such as incident diabetes ${ }^{5,10}$ or rhabdomyolysis. ${ }^{11}$ However, the net benefit of statins may be higher in high-risk groups, such as patients after a first venous thrombosis, and therefore, statins may potentially be useful in secondary prevention of venous thrombosis.

A few observational studies have tried to assess the impact of statin use on recurrent venous thrombosis, with diverging results. Biere-Rafi et al. reported a $50 \%$ reduced risk of recurrent pulmonary embolism in statin users compared with non-users. ${ }^{12}$ Moreover, a 26\% lower risk of recurrent venous thrombosis was found in a Danish registry-based study, ${ }^{13}$ and a $17 \%$ lower risk of recurrence was reported among incident statin users vs non-users. ${ }^{14}$ In contrast, Delluc et al. reported no association between statin intake and recurrent venous thrombosis. ${ }^{15}$ Several methodological aspects of these studies warrant consideration, such as the selection of comparison groups, low statistical power, lack of information on important confounders, and particularly that the majority of the studies did not distinguish between incident and prevalent statin use which may have introduced "incidence/prevalence bias." ${ }^{16}$

Since the role of statins in the prevention of venous thrombosis remains unclear, we set out to determine the association between statin use (both incident and prevalent use) and the risk of recurrent venous thrombosis in a follow-up study of patients who had previously participated in a large population-based case-control study into risk factors for a first venous thrombotic event. Detailed clinical information was available for each individual, which facilitated control for confounding.

\section{2 | METHODS}

Patients were recruited from the Multiple Environmental and Genetic Assessment of risk factors for venous thrombosis (MEGA) study. ${ }^{17,18}$
In MEGA, patients with a first, objectively confirmed episode of venous thrombosis were recruited from 6 anticoagulation clinics in the Netherlands between March 1999 and September 2004, and $86 \%$ of the eligible patients participated. Only patients aged older than 18 years and younger than 70 years were included. In the Netherlands, patients with a thrombotic event are treated at anticoagulation clinics, which are regionally organized. Therefore, all patients living in a certain area are monitored and followed-up by the same clinic, irrespective of the hospital they were admitted to or the physician who started the treatment, allowing population-based studies. Patients with a deep vein thrombosis of the leg, pulmonary embolism, or both were included, and patients with an upper extremity venous thrombosis were excluded. A total of 4,956 patients were eligible for the follow-up study. Of these, 225 indicated that they did not want to participate in a follow-up study, and were therefore excluded (Figure 1). The study was approved by the medical ethics committee of the Leiden University Medical Center and all participants gave their written informed consent.

\section{1 | Initial questionnaire (baseline characteristics)}

Participants were asked to fill in a standardized questionnaire within a few weeks after enrollment in the study. The date of enrollment was defined as the date of first venous thrombosis. The questionnaire provided information on atherosclerotic diseases, body weight and height, smoking status, physical activity, and provoking factors

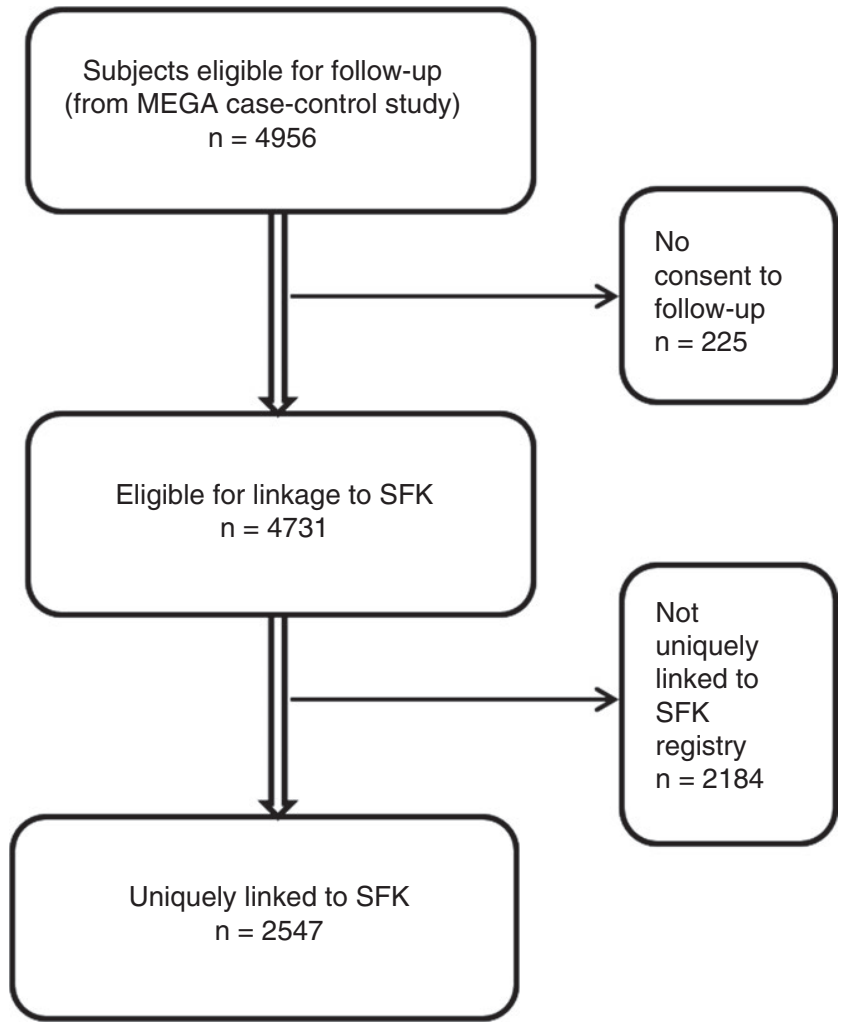

FIGURE 1 Flowchart of study inclusion and linkage to pharmacy database (SFK) 
for venous thrombosis. Provoking factors were defined as recent (within 3 months prior to the index date) leg injury, surgery, pregnancy, or immobilization (plaster cast, bedridden at home, hospitalization), long-distance travel by air, train, bus, or car in the 8 weeks before the index date, estrogen use (oral contraceptives or hormonal replacement therapy) at time of enrollment, and diagnosis of malignancy within 5 years before or within 6 months after enrollment. Atherosclerotic disease was defined as a history of ischemic stroke or myocardial infarction. Body mass index (BMI) was calculated by dividing weight $(\mathrm{kg})$ by height squared $\left(\mathrm{m}^{2}\right)$. Smokers were divided in current, previous, and never smokers. Patients who participated in sports activities at least once a week were considered to be physically active. All other participants were considered to be physically inactive. ${ }^{19}$

\subsection{Exposure to statins and other medications}

Information on statin use at time of enrollment and during follow-up was obtained by linkage to the Dutch Foundation for Pharmaceutical Statistics (SFK) registry. The SFK gathers its data from a panel of nonhospital based pharmacies, covering more than $95 \%$ of the community pharmacies in The Netherlands. The SFK does not contain a unique person identification number, and therefore, linkage was based on a combination of age, sex, 4-digit postal code, and vitamin $\mathrm{K}$ antagonist use within the first month after the initial venous thrombosis. Individuals who could be uniquely identified by these criteria were included in our study, ie, patients with information leading to the identification of more than one person (eg, individuals of the same age and sex, who were living in the same postal code region, and had a prescription of vitamin $\mathrm{K}$ antagonists within the relevant time frame) or to nobody at all (eg, immigrants, visitors) were excluded. In addition, SFK does not gather data from hospital pharmacies. Therefore, if the first month (or longer) of vitamin $\mathrm{K}$ antagonist treatment was received by the patient through the hospital pharmacy, these patients could not be linked to the SFK. In total, 2,547 patients (53.8\%) of the eligible MEGA patients were uniquely identified this way.

The SFK provided information on an individual's prescriptions from community pharmacies in the period January 1999 through December 2008. The information included prescription date, type of drug (generic name and Anatomical Therapeutic Chemical [ATC] classification), amount, and defined daily dosage (DDD). Periods of statin use were defined as series of subsequent prescriptions of either plain statins (ATC code C10AA) or combined preparations (ATC C10BA, C10BX). Treatment was considered to be continued when a new prescription was given within 6 months after the previous prescription. If the gap was longer, a new treatment period was assumed.

\section{3 | Assessment of recurrent venous thrombosis}

Information about potential recurrences was retrieved from the anticoagulation clinics and from the patients themselves. Questionnaires about recurrent events were sent by mail between June 2008 and July 2009 to all patients known to be alive. During the same period, information on possible recurrences of all patients was obtained from the anticoagulation clinic where they were initially included for their first event and in case they moved house, at the clinic near their new address. For all potential recurrences derived from the questionnaire, anticoagulation clinic or both, discharge letters were requested from the clinician who diagnosed the recurrence according to the patient and/or the clinic. The reported recurrences were classified into certain and uncertain recurrences using a clinical decision rule as described elsewhere. $^{20}$

\subsection{Statistical analysis}

Observation time was calculated as the time at risk from the date of the first venous thrombotic event to the end of follow-up. The end of follow-up was defined as the date of recurrence, date of death or emigration, or the date of filling in the short questionnaire. If a patient did not respond to the questionnaire or phone interview, they were censored from the last date we knew them to be recurrence-free (ie, last visit to the anticoagulation clinic or last moment the patient was known to be recurrence-free from information of the MEGA casecontrol study. The analyses were limited to certain recurrent events only, and patients with uncertain recurrent events were censored at that time.

Statistical analyses were performed with STATA version 13.0 (Stata Corporation, College Station, TX, USA). Crude incidence rates (IR) of recurrent venous thrombosis were calculated and expressed as number of events per 1,000 person-years at risk. Cox proportional hazard regression models were used to obtain hazard ratios (HR) for recurrence with $95 \%$ confidence intervals $(\mathrm{Cl})$. Two analyses were conducted. First, an analysis in which prevalent and incident statin users were combined, and in which statin treatment was entered in the model as a time-varying covariable. ${ }^{21}$ This analysis should give a similar estimate of a statin effect to that obtained by an incident-user analysis when the effect is relatively constant over time ${ }^{22}$; however, whether statin's effects on thrombosis risk vary with time is unclear. To test the assumption of a constant effect of statin use to thrombosis risk, we therefore performed a second analysis that was restricted to new users only.

Adjustments for confounding were conducted using 2 different approaches: (1) a multivariable model that included age, sex, body mass index and smoking, and (2) a propensity score model. In contrast to standard adjustment techniques, where usually confounders that are thought to be related to both exposure (statin use) and outcome (recurrent thrombosis) are included in the model, selection of variables in a propensity score includes both confounders and those that are thought to be related to the outcome only. ${ }^{23}$ Therefore, the propensity score included the aforementioned confounders and also physical inactivity, history of CVD, cancer, factor V Leiden, and blood group non-O. The propensity score was calculated by a probit regression model using the "pscore" program in STATA. The derived propensity scores were divided into 5 blocks, and the balancing properties within categories were satisfied. The propensity scores were used in the analyses as an adjusting covariable. 
In a second separate analysis, we estimated the risk of recurrence in statin vs non-statin users when follow-up time was calculated from the date of withdrawal of anticoagulant treatment.

\section{3 | RESULTS}

In total, 2,547 (53.8\%) MEGA patients with a first venous thrombosis were uniquely linked to the SFK registry (Figure 1). Baseline characteristics did not differ between those who were and were not linked (Table 1), which indicates a low likelihood of selection bias in the linkage process.

During a total of 12622 person-years of follow-up (median follow-up time 5.7 years), statin therapy was continued in 153 (6.0\%) and newly initiated in 233 (9.1\%) of the 2,547 patients. Baseline characteristic of patients who did and did not start to use statins during follow-up are presented in Table 2. Statin starters were older and more frequently men, more overweight and obese, and a higher proportion had a history of arterial thrombosis than those who did not use statins. Moreover, the proportion of patients with a first unprovoked event and the proportion with a first pulmonary embolism were higher among those who started to use statins than among those who did not.

There were 367 recurrent venous thrombotic events (overall crude incidence rate: $2.9, \mathrm{Cl}$ 95: 2.6-3.2 per 100 person-years), of which 32 occurred in prevalent plus new statin users, and 16 occurred among new-statin users (Table 3). The HR of venous thrombosis recurrence in incident statin users compared with non-users was 0.76 (Cl 95: 0.461.26) after adjustments for age and sex. After further adjustments for body mass index and smoking, the HR was 0.78 ( $\mathrm{Cl} 95: 0.46-1.31)$, and it became $0.87(\mathrm{Cl} 95: 0.52-1.47)$ when propensity scores were taken into account. Statin use was associated with a HR of $1.04(\mathrm{Cl}$ 95: 0.54-2.00) in patients with an unprovoked first event (HR), and with a HR of $0.64(\mathrm{Cl} 95: 0.27-1.58)$ in those with a provoked first event after adjustment for propensity score. The association was limited to patients with a first deep vein thrombosis in whom statin use was associated with a $25 \%$ reduced risk of recurrence (propensity adjusted HR 0.75, CI 95: 0.33-1.71). In patients with a first pulmonary embolism the propensity adjusted HR was 1.00 (Cl 95: 0.50-1.98). In general, the risk estimates were attenuated when prevalent users were also included in the analyses (Table 3 ). The risk estimates did not materially change when follow-up was restricted to the time after anticoagulation withdrawal (Table S1).

\section{4 | DISCUSSION}

Statin use appeared to be associated with a reduced risk of recurrent venous thrombosis, but not in patients with a first unprovoked event or in patients with a first pulmonary embolism. However, the confidence intervals were wide due to limited study power, and our findings should therefore be interpreted with caution.

Previous studies on the association between statin use and risk of venous thrombosis recurrence have reported somewhat diverging
TAB LE 1 Baseline characteristics of participants who were and were not detected by linkage to the Foundation for Pharmaceutical Statistics (SFK) database. Values are means with standard deviations in brackets, or numbers with percentages in brackets

\begin{tabular}{|c|c|c|}
\hline & $\begin{array}{l}\text { Patients linked } \\
\text { to the SFK } \\
\text { database }\end{array}$ & $\begin{array}{l}\text { Missing patients } \\
\text { (not detected } \\
\text { by SFK linkage) }\end{array}$ \\
\hline \multicolumn{3}{|l|}{ General characteristics } \\
\hline Patients, n (\%) & $2547(53.8)$ & $2184(46.2)$ \\
\hline Age (years) & $50(12)$ & $46(14)$ \\
\hline Sex (\% women) & $1350(53.0)$ & $1217(55.7)$ \\
\hline BMI & $23.5(4.4)$ & $23.2(4.2)$ \\
\hline Overweight & $597(23.4)$ & $467(21.4)$ \\
\hline Obesity & $147(5.8)$ & $113(5.2)$ \\
\hline Missing BMI & 275 (10.8) & $215(9.8)$ \\
\hline \multicolumn{3}{|l|}{ Smoking } \\
\hline Current & $756(29.7)$ & 769 (35.2) \\
\hline Former & $756(29.7)$ & $554(25.4)$ \\
\hline Never & 779 (30.6) & $689(31.5)$ \\
\hline Missing smoking & $256(10.1)$ & $172(7.9)$ \\
\hline Physical inactivity & $1335(52.4)$ & $1181(54.1)$ \\
\hline Missing inactivity & $235(9.2)$ & $156(7.1)$ \\
\hline Myocardial infarction ${ }^{a}$ & $37(1.5)$ & $32(1.5)$ \\
\hline Ischemic Stroke/TIA ${ }^{a}$ & $43(1.7)$ & $44(2.0)$ \\
\hline Total cholesterol (mmol/L) & $5.68(1.16)$ & $5.57(1.08)$ \\
\hline Triglycerides (mmol/L) & $1.65(0.94)$ & $1.58(0.88)$ \\
\hline HDL cholesterol (mmol/L) & $1.32(0.39)$ & $1.30(0.36)$ \\
\hline \multicolumn{3}{|l|}{ Genetic risk factors } \\
\hline Blood group non-O & $1590(62.4)$ & $1323(60.6)$ \\
\hline Missing blood group & 329 (12.9) & 314 (14.4) \\
\hline Factor V Leiden & 344 (13.5) & 308 (14.1) \\
\hline Missing factor $V$ Leiden & $323(12.7)$ & $308(14.1)$ \\
\hline \multicolumn{3}{|l|}{ First VT characteristics } \\
\hline Deep vein thrombosis & $1490(58.5)$ & $1257(57.6)$ \\
\hline Pulmonary embolism & $826(32.4)$ & $723(33.1)$ \\
\hline $\mathrm{DVT}+\mathrm{PE}$ & $231(9.1)$ & 204 (9.3) \\
\hline Unprovoked first event & $740(29.9)$ & $553(26.0)$ \\
\hline Provoked first event & $1735(70.1)$ & $1571(74.0)$ \\
\hline $\begin{array}{l}\text { Surgery/trauma/ } \\
\text { immobilization }\end{array}$ & $1298(51.0)$ & $1143(52.3)$ \\
\hline Malignancy & $247(9.7)$ & $179(8.2)$ \\
\hline Estrogen use & $663(26.0)$ & $687(31.5)$ \\
\hline Pregnancy/puerperium & $86(3.4)$ & $87(4.0)$ \\
\hline
\end{tabular}

aHistory of self-reported myocardial infarction or ischemic stroke/TIA.

results. A French study of 432 patients with a first unprovoked venous thrombosis, followed for a median of 29.5 months, found no association between statin use and risk of recurrence. ${ }^{15}$ In contrast, a Dutch register-based study of 3,093 patients hospitalized for pulmonary embolism followed for a median of 4 years found that statin use was 


\begin{tabular}{|c|c|c|c|}
\hline & Non-statin users & $\begin{array}{l}\text { Prevalent + new } \\
\text { statin users }\end{array}$ & New statin users \\
\hline \multicolumn{4}{|l|}{ General characteristics } \\
\hline Patients (n) & $2161(90.3)$ & $386(15.2)$ & $233(9.3)$ \\
\hline Age (years) & $49(12)$ & $56(9)$ & $55(9)$ \\
\hline Sex (\% women) & $1182(54.7)$ & $168(43.5)$ & $98(42.1)$ \\
\hline Overweight & 761 (35.3) & $175(45.3)$ & $99(42.5)$ \\
\hline Obesity & $394(18.2)$ & $86(22.2)$ & $56(24.0)$ \\
\hline Current smoking & 647 (29.9) & $109(28.2)$ & $75(32.2)$ \\
\hline Physical inactivity & $1118(51.7)$ & $217(56.2)$ & $134(57.5)$ \\
\hline $\begin{array}{l}\text { History of arterial } \\
\text { thrombosis }\end{array}$ & $31(1.4)$ & $47(12.1)$ & $12(5.2)$ \\
\hline \multicolumn{4}{|l|}{ Genetic risk factors } \\
\hline Blood group non-O & $1354(62.7)$ & $236(61.1)$ & $143(61.4)$ \\
\hline Factor V Leiden & $290(13.4)$ & $54(14.0)$ & $32(13.7)$ \\
\hline \multicolumn{4}{|l|}{ First VT characteristics } \\
\hline Deep vein thrombosis & $1297(60.0)$ & $193(50.0)$ & $115(49.4)$ \\
\hline Pulmonary embolism & $864(40.0)$ & $193(50.0)$ & $118(50.6)$ \\
\hline Unprovoked first event & $594(27.5)$ & $146(37.8)$ & $88(37.8)$ \\
\hline Provoked first event & $1505(69.6)$ & $230(59.6)$ & $140(60.1)$ \\
\hline $\begin{array}{l}\text { Surgery/trauma/ } \\
\text { immobilization }\end{array}$ & 1109 (51.3) & $189(50.0)$ & $130(48.5)$ \\
\hline Malignancy & $215(9.9)$ & $32(8.3)$ & $12(5.2)$ \\
\hline Estrogen use & $617(28.6)$ & $46(11.9)$ & $31(13.4)$ \\
\hline Pregnancy/puerperium & $84(3.9)$ & $2(0.5)$ & $2(0.9)$ \\
\hline
\end{tabular}

TABLE 2 Baseline characteristics of patients who did and did not use statins during follow up. Values are means with standard deviations in brackets, or numbers with percentages in brackets

$\mathrm{VT}$, venous thrombosis.

Prevalent statin users denotes those who used statins at baseline. New statin users denotes those who started using statins for the first time during follow-up.

associated with $50 \%$ reduction of recurrent pulmonary embolism. ${ }^{12} \mathrm{~A}$ register-based study from Denmark, which included 44,330 patients with venous thrombosis followed for a median of 3 years, found that prevalent statin use was associated with a $26 \%$ reduced risk of venous thrombosis. ${ }^{13}$ In this study, statin use appeared to have more influence on the risk of recurrent DVT (34\% reduced risk), while the risk of recurrent pulmonary embolism was only modestly reduced (13\%). ${ }^{13}$ Another publication based on Danish registry data, showed that the adjusted hazard ratio for recurrent venous thrombosis was $0.83(\mathrm{Cl}$ 95: 0.45-1.52) in incident statin users vs non-users. ${ }^{14}$ In a recent study from the US, Smith and colleagues reported that statin users had $26 \%$ lower risk of recurrence than non-users, and that the effect was stronger among patients without previous CVD (38\%). ${ }^{24}$

Even though randomized clinical trials are the preferred strategy to determine effectiveness and safety of drug interventions, much information can be derived from observational studies. However, in order to get the most valid results, observational studies should attempt to mimic clinical trials. In our study, the underlying research question at hand was "should patients with a first venous thrombosis start using statins to prevent recurrence?" Because of this, we conducted our analyses both with patients who were already using statins at baseline and in analyses restricted to those who started statins. Most previous studies on statin use and recurrent venous thrombosis included both prevalent and incident statin users. ${ }^{12-15}$ Prevalent users have by definition responded and survived treatment without major side-effects. Therefore, if statin reduces the risk of venous thrombosis, the group of prevalent users will be enriched with healthier patients, and inclusion of prevalent users will introduce a selection bias that is likely to overestimate a possible protective effect. ${ }^{16}$ Moreover, since confounders are measured after treatment initiation in prevalent users, residual confounding will bias the results when the treatment affects these confounders. ${ }^{25}$ Contrary to this, we found that the risk estimates pointed towards a stronger association in subjects who started statins than in those who were already on statins (prevalent users). Our study population consisted of relatively young subjects (18-70 years), and since the guidelines for prescribing statins differs with regards to age, ${ }^{26}$ use of statins in this young population may not necessarily reflect healthy users in the same way as in the elderly. Moreover, prevalent users have reached the thrombosis threshold ${ }^{27}$ and developed a first venous thrombosis despite the fact that they were using statins, and could therefore be more likely to get a recurrence when on statins. Our findings are supported by the study by Smith et al., ${ }^{24}$ who also reported a stronger association when the analyses were restricted to incident statin users. 
TABLE 3 Risk of recurrent venous thrombosis by use of statins

\begin{tabular}{|c|c|c|c|c|c|}
\hline & & & Age and sex adjusted & Multivariable adjusted & $\begin{array}{l}\text { Propensity } \\
\text { score adjusted }\end{array}$ \\
\hline & PY & Events & $\mathrm{HR}(95 \% \mathrm{Cl})$ & HR $(95 \% \mathrm{Cl})$ & $\mathrm{HR}(95 \% \mathrm{Cl})$ \\
\hline No use & 11551 & 335 & 1 (reference) & 1 (reference) & 1 (reference) \\
\hline Prevalent + new use & 1071 & 32 & $0.86(0.60-1.25)$ & $0.89(0.61-1.30)$ & $0.92(0.62-1.35)$ \\
\hline \multicolumn{6}{|l|}{ Deep vein thrombosis } \\
\hline No use & 6700 & 207 & 1 (reference) & 1 (reference) & 1 (reference) \\
\hline Prevalent + new use & 530 & 17 & $0.90(0.55-1.48)$ & $0.89(0.52-1.51)$ & $0.91(0.52-1.57)$ \\
\hline New use & 290 & 7 & $0.70(0.33-1.49)$ & $0.66(0.29-1.48)$ & $0.75(0.33-1.71)$ \\
\hline New use & 313 & 9 & $0.85(0.43-1.69)$ & $0.91(0.46-1.80)$ & $1.00(0.50-1.98)$ \\
\hline \multicolumn{6}{|l|}{ Unprovoked } \\
\hline No use & 3222 & 145 & 1 (reference) & 1 (reference) & 1 (reference) \\
\hline Prevalent + new use & 423 & 17 & $0.92(0.55-1.53)$ & $0.96(0.57-1.63)$ & $0.93(0.55-1.57)$ \\
\hline New use & 242 & 11 & $1.04(0.56-1.92)$ & $1.03(0.54-1.98)$ & $1.04(0.54-2.00)$ \\
\hline \multicolumn{6}{|l|}{ Provoked } \\
\hline No use & 8094 & 182 & 1 (reference) & 1 (reference) & 1 (reference) \\
\hline Prevalent + new use & 611 & 14 & $0.79(0.45-1.37)$ & $0.77(0.43-1.36)$ & $0.89(0.50-1.58)$ \\
\hline New use & 349 & 5 & $0.50(0.20-1.21)$ & $0.53(0.22-1.29)$ & $0.64(0.27-1.58)$ \\
\hline
\end{tabular}

$\mathrm{Cl}$, confidence interval; HR, hazard ratio; PY, person years; Multivariable model: age, sex, body mass index and smoking.

The previous studies on statins and venous thrombosis recurrence showed diverging results. Some of these differences may be explained by differences in study design and study population. The most pronounced protective effect of statin use was found in the Dutch study of patients hospitalized for pulmonary embolism, ${ }^{12}$ which contrasts our finding of no apparent association between statins and pulmonary embolism. In addition to including prevalent statin users, which may have overestimated the positive effect in this study, the patients were censored after their last prescription. ${ }^{12}$ The latter indicates that patients for whom medications were no longer collected from a community pharmacy (ie, the healthier or perhaps terminally ill patients) were censored during follow-up. Since statin users use a prescription drug by definition, it is likely that more non-statin users were removed from the study, and this may have introduced selection bias that obscured the true effect. Although our results on statin use were insufficiently powered to draw definite conclusions, the risk estimates obtained for incident users in our study are similar to those of the large Danish registry-based studies, ${ }^{13,14}$ and the studies from the US ${ }^{24}$ and Canada. ${ }^{28}$ The study by Delluc et al. ${ }^{15}$ included patients with unprovoked venous thrombosis only, and found no association between statin use and risk of recurrence (HR: 1.02). When we restricted our analyses to those with unprovoked venous thrombosis, we found similar results. In contrast, the Danish study ${ }^{14}$ reported a lower risk of recurrence among statin users regardless of the unprovoked/provoked nature of the first event. We found that statin use potentially protected against recurrence in patients with a first provoked venous thrombosis. The characteristics of the provoking factors related to the first event may have played a role in this finding, since for instance cancer patients, who have the highest risk of recurrence, could be less likely to start using statins.

The issue of statistical power is of critical importance for proper interpretation of risk estimates. So, although our results were insufficiently powered, based on the point estimates and confidence intervals from the Cox-regression analyses, we cannot rule out the possibility of a modestly reduced risk of venous thrombosis associated with statin use. Furthermore, our study did not have sufficient statistical power to investigate types of statins and the impact of the size of the daily dosage. A strength of our study was the detailed baseline information on potential confounders such as body mass index, smoking, physical activity, history of co-morbidities, and blood group, and we could adjust for these in the multivariable and propensity score models. Unfortunately, we did not have information on cardiovascular events during follow-up, and could therefore not investigate or adjust for this potential confounding.

In conclusion, our findings suggest that statins may at most have a modest effect on risk of recurrent venous thrombosis. Although 
the confidence intervals were wide, the point estimates indicated no association between statin use and risk of recurrence in those with an unprovoked first event or those with a first pulmonary embolism. This latter finding sheds doubt on the existence of a true association between statin use and the risk of recurrent thrombosis. A large metaanalysis of venous thrombosis cohorts is warranted to further investigate the association between incident statin use and risk of recurrent venous thrombosis.

\section{ACKNOWLEDGMENTS}

We express our gratitude to all individuals who participated in the MEGA study, and to the staff involved in the execution of the study. This work was supported by the Netherlands Heart Foundation (grants NHS98.113, NHS2010B167, NHS208B086, and NHS2011T012), the Dutch Cancer Foundation (RUL 99/1992), and the Netherlands Organization for Scientific Research (grant 912-03-033|2003). The Netherlands Heart Foundation, the Dutch Cancer Foundation and the Netherlands Organization for Scientific Research played no role in the design and conduct of the study, the collection, management, analysis and interpretation of the data, the preparation, review and approval of the manuscript, or the decision to submit the manuscript for publication.

\section{AUTHOR CONTRIBUTIONS}

SKB analyzed the data and drafted the manuscript. CCD and SleC provided statistical expertise. BS contributed to the study design and data interpretation. AvHV was involved in data collection and design of the study. FRR was responsible for data collection (the MEGA study), SCC and WML contributed to conception and design of the study and interpretation of the results. All authors critically revised the manuscript for important intellectual content and approved the final version of the paper.

\section{RELATIONSHIP DISCLOSURE}

The authors report no potential conflicts of interest.

\section{REFERENCES}

1. Naess IA, Christiansen SC, Romundstad P, Cannegieter SC, Rosendaal FR, Hammerstrom J. Incidence and mortality of venous thrombosis: a population-based study. J Thromb Haemost. 2007;5: 692-9.

2. Christiansen SC, Cannegieter SC, Koster T, Vandenbroucke JP, Rosendaal FR. Thrombophilia, clinical factors, and recurrent venous thrombotic events. JAMA. 2005;293:2352-61.

3. Sorensen HT, Horvath-Puho E, Lash TL, et al. Heart disease may be a risk factor for pulmonary embolism without peripheral deep venous thrombosis. Circulation. 2011;124:1435-41.

4. Sorensen HT, Horvath-Puho E, Pedersen L, Baron JA, Prandoni P. Venous thromboembolism and subsequent hospitalisation due to acute arterial cardiovascular events: a 20-year cohort study. Lancet. 2007;370:1773-9.
5. Mills EJ, Wu P, Chong G, et al. Efficacy and safety of statin treatment for cardiovascular disease: a network meta-analysis of 170,255 patients from 76 randomized trials. QJM. 2011;104:109-24.

6. Grundy SM, Cleeman JI, Merz CN, et al., National Heart, Lung, and Blood Institute; American College of Cardiology Foundation; American Heart Association. Implications of recent clinical trials for the National Cholesterol Education Program Adult Treatment Panel III guidelines. Circulation. 2004;110:227-39.

7. Glynn RJ, Danielson E, Fonseca FA, et al. A randomized trial of rosuvastatin in the prevention of venous thromboembolism. N Engl J Med. 2009;360:1851-61.

8. Rahimi K, Bhala N, Kamphuisen P, et al. Effect of statins on venous thromboembolic events: a meta-analysis of published and unpublished evidence from randomised controlled trials. PLoS Med. 2012;9:e1001310.

9. Squizzato A, Galli M, Romualdi E, et al. Statins, fibrates, and venous thromboembolism: a meta-analysis. Eur Heart J. 2010;31: 1248-56.

10. Sattar N, Preiss D, Murray HM, et al. Statins and risk of incident diabetes: a collaborative meta-analysis of randomised statin trials. Lancet. 2010;375:735-42.

11. Armitage J. The safety of statins in clinical practice. Lancet. 2007;370:1781-90.

12. Biere-Rafi S, Hutten BA, Squizzato A, et al. Statin treatment and the risk of recurrent pulmonary embolism. Eur Heart J. 2013;34: 1800-6.

13. Nguyen CD, Andersson C, Jensen TB, et al. Statin treatment and risk of recurrent venous thromboembolism: a nationwide cohort study. BMJ Open. 2013;3:e003135.

14. Schmidt M, Cannegieter SC, Johannesdottir SA, Dekkers OM, Horvath-Puho E, Sorensen HT. Statin use and venous thromboembolism recurrence: a combined nationwide cohort and nested casecontrol study. J Thromb Haemost. 2014;12:1207-15.

15. Delluc A, Tromeur C, Le Moigne E, et al. Lipid lowering drugs and the risk of recurrent venous thromboembolism. Thromb Res. 2012;130:859-63.

16. Danaei G, Tavakkoli M, Hernan MA. Bias in observational studies of prevalent users: lessons for comparative effectiveness research from a meta-analysis of statins. Am J Epidemiol. 2012;175: 250-62.

17. Blom JW, Doggen CJ, Osanto S, Rosendaal FR. Malignancies, prothrombotic mutations, and the risk of venous thrombosis. JAMA. 2005;293:715-22.

18. Bezemer ID, Bare LA, Doggen CJ, et al. Gene variants associated with deep vein thrombosis. JAMA. 2008;299:1306-14.

19. van Stralen KJ, Le Cessie S, Rosendaal FR, Doggen CJ. Regular sports activities decrease the risk of venous thrombosis. J Thromb Haemost. 2007;5:2186-92.

20. Timp JF, Lijfering WM, Flinterman LE, et al. Predictive value of factor VIII levels for recurrent venous thrombosis: results from the MEGA follow-up study. J Thromb Haemost. 2015;13:1823-32.

21. Stricker BH, Stijnen T. Analysis of individual drug use as a time-varying determinant of exposure in prospective population-based cohort studies. Eur J Epidemiol. 2010;25:245-51.

22. Vandenbroucke J, Pearce N. Point: incident exposures, prevalent exposures, and causal inference: does limiting studies to persons who are followed from first exposure onward damage epidemiology? Am J Epidemiol. 2015;182:826-33.

23. Brookhart MA, Schneeweiss S, Rothman KJ, Glynn RJ, Avorn J, Sturmer T. Variable selection for propensity score models. Am J Epidemiol. 2006;163:1149-56.

24. Smith NL, Harrington LB, Blondon M, et al. The association of statin therapy with the risk of recurrent venous thrombosis. J Thromb Haemost. 2016; 14: 1384-92. 
25. Hernan MA, Hernandez-Diaz S, Robins JM. A structural approach to selection bias. Epidemiology. 2004;15:615-25.

26. Stone NJ, Robinson JG, Lichtenstein AH, et al., American College of Cardiology/American Heart Association Task Force on Practice Guidelines. 2013 ACC/AHA guideline on the treatment of blood cholesterol to reduce atherosclerotic cardiovascular risk in adults: a report of the American College of Cardiology/American Heart Association Task Force on Practice Guidelines. J Am Coll Cardiol. 2014; 63: 2889-934.

27. Rosendaal FR. Venous thrombosis: a multicausal disease. Lancet. 1999; 353: 1167-73.

28. Tagalakis V, Eberg M, Kahn S, Azoulay L. Use of statins and reduced risk of recurrence of VTE in an older population. A population-based cohort study. Thromb Haemost. 2016;115:1220-8.

\section{SUPPORTING INFORMATION}

Additional Supporting Information may be found online in the supporting information tab for this article.

How to cite this article: Brækkan SK, Caram-Deelder C, Siegerink B, et al. Statin use and risk of recurrent venous thrombosis: results from the MEGA follow-up study.

Res Pract Thromb Haemost. 2017;1:112-119.

https://doi.org/10.1002/rth2.12003 